visual flight is difficult. If he makes the transition at $250 \mathrm{ft}$., then he will be flying on visual references for only 30 sec. prior to touch-down. With improved instrumentation the aircraft could perhaps be brought down to $100 \mathrm{ft}$., in which case this time would be reduced to 15 sec. The problem is, therefore, to find a pattern for the approach lights which will provide indications which the pilot can interpret instantly without having to use mental processes different from those which he has learnt to use in good-weather flying.

The first patterns to be tried consisted of single and multiple lines parallel to the extended centre-line of the runway, and these were followed by vees and funnels. Flight tests on these patterns extending over several years showed that in bad visibility the impressions of the pilot when he first picks up the lights often fail to correspond with the real situation. In other words, his first impressions are often illusions. Three illusions are commonly reported as follows: (1) The runway lights appear to 'float in space', or 'stand on end', that is, they appear as an inverted vee in the vertical plane instead of a pair of parallel lines in the horizontal plane. Also the pattern has 'no depth' and appears to be at a varying distance. As a result the pilot 'Ioses his ground plane' and has a strong impulse to pull up. (2) The approach lights appear to 'swing from side to side' or 'drift out of the field of view', so that instead of descending on a straight course, the pilot 'weaves' from side to side. (3) A strong impression of the horizon is suddenly built up in the pilot's mind, although he knows that he cannot tell where the horizon is without referring back to his instruments. When the pilot is suffering from fatigue or is in a state of mental stress, this conflict causes feelings of confusion and frustration, and in extreme cases of vertigo.

These illusions have been studied statically by means of perspective diagrams, and kinematically by means of landing simulators. It was found that when the effect of fog is simulated by removing the horizon, the visual indications become geometrically indeterm. inate. In other words, the same picture represents a large number of different situations. If, therefore, a pilot tries to correct an error by observing only the visual indications, he can scarcely avoid being confused by their ambiguity.

Mr. Calvert then showed that the indications can be made geometrically determinate by using a pattern consisting of a line of lights along the centre-line with bars of lights running transversely across it at intervals. The reason for this is that the bars supply the indication of the horizontal which is missing in the other patterns. This pattern, which is now known as the 'crossbar system', was installed at London Airport in November 1948, and shortly afterwards about a dozen installations were laid down in Germany, mostly for the 'Berlin Air Lift'. All reports agree that the transition is consistently easy and safe, and no illusions have been reported.

Mr. Calvert then described a new theory of visual judgment which has been developed as a result of collaboration between Capt. Majendie of B.O.A.C. and his own group at the Royal Aircraft Establishment. This theory, which is known as the 'parafoveal streamer theory', is briefly as follows. When the aircraft is several miles from the runway the angular subtense of the pattern and the rate of change of the perspective image are small, and the pilot makes his judgments by scanning the pattern and comparing the perspective image with an ideal one which he carries in his memory. As the aircraft comes closer to the pattern, its angular subtense and the apparent velocity of the lights increase. At about $150 \mathrm{ft}$. the pilot begins to stare straight ahead with his head and eyeballs fixed. After this, he derives his impressions of height and direction of motion mainly from the pattern formed by the paths which the retinal images of the lights trace out on the parafovea, and from the velocity of the images along these paths. These paths may be called 'streamers', the pattern a 'streamer pattern', and the image velocity the 'streamer velo. city'. The reason why the pilot stares is that it is easier to judge streamer patterns and streamer velocities if he keeps his eyeballs fixed, because in that case the only changes in the retinal image are those due to changes in the streamer pattern and streamer velocities.

Capt. Majendie opened the discussion by showing a film which he had taken of the faces of various pilots when making landings. These showed clearly that at heights below about $150 \mathrm{ft}$. the pilot's head is rigid, and the eyes are staring straight ahead, except for occasional quick glances at an instrument or an obstruction. The film also showed some calibrated eye-movements which indicated that a movement of $1^{\circ}$ could just be detected.

Mr. Glenny then showed some films of landings in very bad visibility which had been made in America by the Sperry Gyroscope Co. These also showed a high degree of fixated vision at low heights. A noticeable feature of both films was the expression of strain on the faces of the pilots.

Mr. Parker, speaking on behalf of the Ministry of Civil Aviation, said that the 'crossbar system' at London Airport has been very successful. During the past two winters many landings with passengers have been made on it in visibilities as low as 300 yards. The principles on which it is based are now generally accepted in Great Britain, and are being increasingly accepted abroad. It is one of three systems recommended by the International Civil Aviation Organisation, and about eight foreign countries are already installing it at their major airports. It is therefore quite possible that the 'crossbar system' will become the standard approach lighting system of the future.

\section{PERIODIC FLUCTUATION IN THE LENGTH OF THE DAY}

A PAPER by H. F. Finch "On a Periodic Fluctuation in the Length of the Day"1 gives a full account of the performance of a number of quartzcrystal clocks employed in the Greenwich Time Service. Soon after the introduction of quartz clocks, their errors on a long-term basis were predicted, and the clock correction $E$ was represented very closely by the expression $E=a+b t+c t^{2}$, where $t$ is reckoned in time from some arbitrary epoch, and $a, b, c$ are constants the values of which were derived from a series of time determinations extending over many months.

By applying the adopted current corrections to the standard clocks and using daily intercomparisons, it was possible to deduce the amount of correction for the clock controlling the time signal, prior to transmission. Although the method succeeded for a time, in the autumn of 1945 the observed clock corrections began to diverge from those predicted, the clocks 
appearing to have undergone an acceleration of rate, and a retardation in the period of rotation of the earth was suspected. In subsequent years, as more clocks became available, the same phenomenon was in evidence, but it was not until the spring of 1949 that a definite retardation among a number of clocks was noticed. The suspicion of a seasonal fluctuation in the earth's period of rotation led to an examination of the final corrections to the times of emission of the Rugby time signals which are under the control of the Greenwich Time Service, and a full account of the investigations and the conclusions is given in Finch's paper.

It appears that there is a variation of the order 0.001 sec. and an accumulative effect in time of approximately 0.060 sec. Similar results were obtained by N. Stoyko ${ }^{2}$, who published his investiga. tions during 1936-37, but his work did not receive mueh attention at the time. An attempt to account for the phenomena of the slowing of the earth in spring and of its acceleration in the autumn was made by van den Dungen, Cox and van Miegham ${ }^{3}$, who used observations of the barometric pressure over the surface of the earth at different seasons. They showed that the effect could be accounted for in part by changes in the earth's moment of inertia due to seasonal changes in the distribution of air masses, but owing to incomplete data further investigation is required.

It may be pointed out that Chapter 5 of "The Atmospheres of the Earth and Planets", edited by Prof. G. P. Kuiper, deals with the work of Whipple, Jacchia and Kopal on seasonal changes in the upper regions of the atmosphere. The whole upper atmosphere at a height of about $78 \mathrm{~km}$. appears to rise in spring by 8 or $9 \mathrm{~km}$. and to drop again by the same amount in the autumn. No reference is made in Finch's paper to this phenomenon, which may have to be taken into account in future explanations of the seasonal changes in the earth's rate of rotation. The fluctuation of approximately annual period in the mean longitude of the moon, deduced from occultation observations, is much too large to be explained by the variations in the rotation of the earth.

${ }^{1}$ Mon. Not. Roy. Astro. Soc., 110, 1 (1950).

' C.R. Acad., Paris, 203, 39 (1936); 205, 79 (1937).

B Bul. Cl. Sci. Acad. roy. Belgique, 5, Series 35 (1949).

\section{PACIFIC SCIENCE BOARD}

\section{ANNUAL REPORT FOR 1949}

$\mathrm{T}$ HE third annual report of the Pacific Science Board, covering the year 1949*, reviews briefly the work of the Seventh Pacific Science Congress, which was convened at Auckland and Christchurch during February 2-22, 1949; the Congress was attended by representatives of twenty-four countries, and more than five hundred papers were presented. Plans are now well advanced for the publication of the proceedings of the Congress, and the present report lists some articles describing the work of the Congress in general or in specific fields.

The Co-ordinated Investigation of Micronesian Anthropology programme consisted largely of continuing work by the participants on their final reports,

* Paciflc Science Board. Third Annual Report, 1949. Pp. 154. (Washington, D.C.: National Research Council, 1950.) of which twenty-six have now been accepted by the Board. The titles of these are listed in the report of the Board, and the reports are expected to be pub. lished by the sponsoring institutions or in appropriate scientific journals. The proposal to appoint three anthropologists to the staffs of the civil administrators in the Palau, Truk and Marshall Islands could not be implemented in 1949; but five anthropologists are already used by the United States Navy in its Civil Administration Units in the Trust Territory. The programme was extended in March 1949 to include other fields of science and is known as Scientific Investigations in Micronesia. Ten participants were appointed to carry out field work in the Trust Territory in anthropology, linguistics, botany and zoology.

The Insect Control Committee for Micronesia has sponsored a detailed study of Achatina fulica in various islands in the Trust Territory with the view of determining the variation in populations, extent of damage to crops, local predators, etc., and has sent a technician to investigate the possibility of processing it for human or animal food. Reports have been received that the wasp, Scolia ruficornis, that preys on the rhinoceros beetle (Oryctes rhinoceros) has become well established in western Samoa. Under the Conservation Committee for Micronesia, problems of the trochus shell (Trochus niloticus) fishery and of the robber or coconut crab (Birgus latro) have been investigated, as well as the damage to water supply and agricultural land resulting from mining operations on Angaur in the Palaus.

As a result of a report by Dr. C. J. Fish with Mary C. Cobb on "Noxious Marine Animals of the Central and Western Pacific", the Pacific Science Board has been requested by the United States Office of Naval Research to consider the preparation of a handbook that could be used by those stationed in the area on poisonous and otherwise dangerous animals in the Central and Western Pacific. Prospects for the realization of the high purpose of furthering scientific research in the Pacific through the agency of the Pacific War Memorial, which was established as a scientific foundation dedicated as a living memorial to those who served with the Armed Forces of the United States in the Pacific, depend on the availability of substantial support which has not yet materialized. Details of the Fulbright programme are included in the report, as well as a summary of the initial programme of the South Pacific Research Council for 1949-50.

Field projects approved by the Board include a Pilot Nutrition Study in Micronesia, with special reference to children, a mid-Pacific oceanographic project, a serological survey of the Pacific area, an anthropological and ethnographical study of the Southern Rynkyn Islands, a botanical study of New Caledonia, a filariasis survey of Tahiti, a study of diabetes mellitus in Guam, an anthropological and archæological survey of Saipan and an ethnological study of the Gilbert and Ellice Islands. Substantial progress is being made through the co-operation of the United Nations Social and Economic Council and its specialized agencies in awakening countries of the Pacific Area to the urgent need for taking measures to conserve their renewable natural resources. During the year the executive secretary of the Pacific Science Board visited the French Institute of Oceania, at Noumea, which it is hoped will increasingly become a base for international co-operative research in various fields of science. 